\title{
COMPUTER SIMULATIONS
}

\section{RWMODEL: A program in Turbo Pascal for simulating predictions based on the Rescorla-Wagner model of classical conditioning}

\author{
H. LACHNIT, R. L. SCHNEIDER, and O. V. LIPP \\ University of Giessen, Giessen, Federal Republic of Germany \\ and \\ H. D. KIMMEL \\ University of South Florida, Tampa, Florida
}

\begin{abstract}
A Turbo Pascal computer program is described that simulates the Rescorla-Wagner model of classical conditioning. The menu-driven program makes it possible to compute associative strengths for differential conditioning, conditioned inhibition, compound and contextual conditionings, transswitching, and other designs.
\end{abstract}

The Rescorla-Wagner model of classical conditioning (Rescorla \& Wagner, 1972) has had a profound impact on Pavlovian conditioning research over the past 15 years (e.g., Mackintosh, 1983). Beginning with its successful handling of the phenomena of blocking (Kamin, 1968) and overshadowing (Pavlov, 1927), the model has proved to be a highly flexible and versatile tool for the elucidation of the processes underlying a variety of Pavlovian conditioning results.

The Rescorla-Wagner model characterizes the trial-bytrial growth in associative strength in terms of a linear equation,

$$
\Delta V_{X}=(\alpha)(\beta)\left(\lambda-V_{A X}\right),
$$

in which the change in associative strength $(\Delta V)$ of stimulus $X$ depends upon the difference between the maximum associative strength supportable by the unconditioned stimulus $(\lambda)$ and the sum of the currently existing associative strengths of the stimuli present on that trial, here identified as $A$ and $X . \alpha$ and $\beta$ are learning rate parameters detemined by the salience of the stimuli and the reinforcement, respectively. It is assumed, for simplicity, that

$$
V_{A X}=V_{A}+V_{X}
$$

RWMODEL is a program written in Turbo Pascal for computing associative strengths accruing to the stimuli in a classical conditioning experiment, according to the Rescorla-Wagner model. The program makes it possible to compute associative values for a wide range of classi-

The current version of the program was developed by Roland $L$. Schneider. Address correspondence to Harald Lachnit, Department of Psychology, University of Giessen, Otto-Behaghel-Strasse/10, 6300 Giessen, Federal Republic of Germany. cal conditioning designs, including differential conditioning, conditioned inhibition, compound conditioning, contextual conditioning, transswitching, and so forth. Up to 10 different conditioned stimulus elements in a compound can be handled.

The menu-driven program has its own editor and makes use of graphics to enhance numerical presentations. The menu provides the following options: READ problem description file, WRITE problem description file, EDIT problem description file, PRINT simulation to screen, PLOT simulation to screen (or graphics printer), WRITE results of simulation to file, HELP options, and QUIT program.

The description files contain several statements (e.g., title, design, data, astrength, $y$-axis, output, and @file). These statements define the problem and the parameters of the model and choose the kind of computation and output desired. The "data" statement permits empirical values to be added for comparison with simulated values. The "@file" statement allows external files to be read into the problem description file at any desired point. This facilitates repeated computations with particular parameters.

The program is accompanied by a user's guide, a tatorial, and six supplementary examples taken from Rescorla and Wagner (1972), as well as three additional instructional examples. In addition, there is an "auto-exec" file (RWMODEL.BAT), which allows plotting of simulations on screen with a graphics printer by means of the "printscreen" key.

The simplicity of the program can be exemplified by one of the instructional examples. Here, the well-known phenomenon of blocking (Kamin, 1968) is illustrated. The problem description file for this example, which is called 
to the screen by entering $E$ (for Edit), contains the following instruction:

$$
\begin{aligned}
& \text { Title = Blocking; } \\
& \text { Design = 10a+,10ax+; } \\
& \text { lambda }(+)=1.0 ; \\
& \text { astrength }(\mathrm{a})=0 ; \\
& \text { astrength }(\mathrm{x})=0 ; \\
& \text { Output }(\mathrm{a}, \mathrm{x}, \mathrm{ax})=\text { long; }
\end{aligned}
$$$$
\text { beta }(+)=0.135 \text {; }
$$$$
\text { alpha (a) }=1.0 \text {; }
$$$$
\text { alpha }(x)=1.0 \text {; }
$$

The design statement indicates that stimulus $A$ is presented for 10 trials with reinforcement. Following this, a compound of $A$ and $X$ are presented for 10 trials with reinforcement. Lambda, the limit of associative strength supportable by the unconditioned stimulus is set at 1.0 for reinforced trials. Beta, the learning rate parameter associated with the unconditioned stimulus, is set at 0.135 for reinforced trials, to ensure rapid growth of associative strength of stimulus $A$ during the first 10 trials, so that clear evidence of blocking will be seen in the compound trials 11-20. Alphas for stimulus $A$ and $X$ are both set at 1.0 , indicating that the two stimuli are equally conditionable. Astrength is the value of associative strength at the beginning of the sequence; in the example, it is set to 0 . The output statement indicates that associative strengths of both single stimuli, $A$ and $X$, and of the compound of $A+X$ are desired. The "long" output indicates that all of the trials will be calculated (a "short" option can be used when only selected trials are of interest). A plot of the results of this simulation, achieved by selecting $\mathrm{L}$ from the main menu, is shown in Figure 1. As can be seen in Figure 1, reinforcement of stimulus $A$ for 10 trials is predicted by the model to result in rapid growth of associative strength of both stimulus $A$ and the compound $A+X$. Reinforcement of the $A+X$ compound for the next 10 trials, however, causes almost no growth in associative strength of stimulus $X$, since the RescorlaWagner model predicts that the presence of stimulus $A$ in the compound leaves almost no difference remaining between maximal associative strength and current associative strength (since $A$ has already risen almost to 1.0 in the first 10 trials).

RWMODEL is intended for use by both professional scientists and students. The ease with which design changes can be introduced and quickly simulated greatly expands the potential of the Rescorla-Wagner theory for generating new experiments and new directions for experiments. Previous computer programs simulating the Rescorla-Wagner model (e.g., Bond \& Siddle, 1987), although useful as instructional aids, do little more than illustrate the way in which the model handles certain standard experimental paradigms. RWMODEL enables the user to create almost any conditioning design desired and to simulate the results predicted by the Rescorla-Wagner model. Discrepancies between actual data and predictions

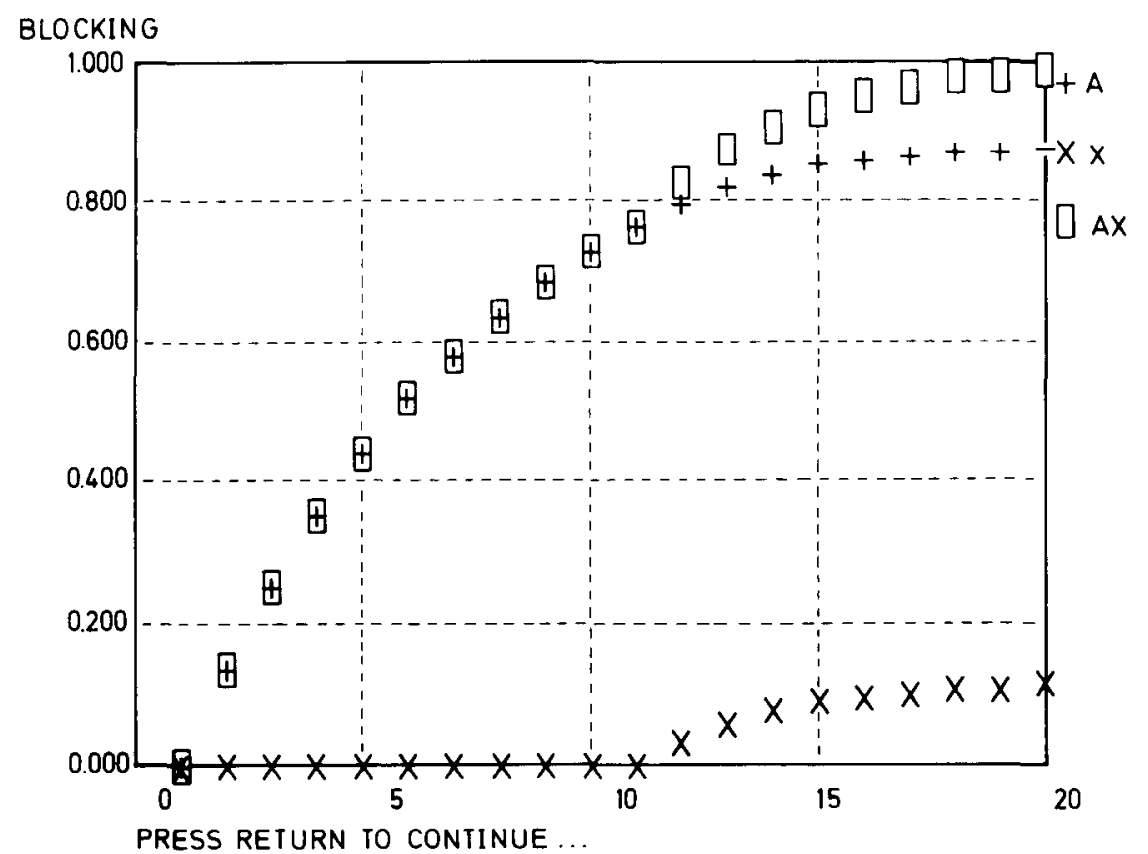

Figure 1. An RWMODEL simulation of a blocking experiment, with 10 reinforced trials of stimulus $A$ followed by 10 reinforced trials of compound stimulus $A+X$. Associative strengths of $A, X$, and $A+X$ are shown. 
from the model can be analyzed by means of iterative changes in model parameters (e.g., Kimmel \& Lachnit, in press), in an effort to discover the causes of these discrepancies and possible modifications or addenda to the model that might eliminate them.

RWMODEL is written in Borland Turbo Pascal, Version 3.0. The program runs under PC DOS, Version 3.1 or higher, on a standard IBM PC. Any IBM-compatible PC meets the maximum storage requirements (less than 256K). Program versions are available for systems with CGA, Hercules, and ECA graphics cards. Programs may be obtained from Harald Lachnit, Department of Psychology, University of Giessen, Otto-Behaghel-Strasse 10, 6300 Giessen, Federal Republic of Germany. A 5.25-in. diskette containing the computational program, user's guide, tutorial, and examples is available for $\$ 15$ (to cover the costs of the diskette and mailing).

\section{REFERENCES}

Bond, N. W., SiddeE, D. A. T. (1987). Learning and motivation: Computer simulations of the Rescorla-Wagner, Solomon-Corbit, and Schull models. Behavior Research Methods, Instruments, \& Computers, 19, 404-406.

KAMIN, L. J. (1968). Attention-like processes in classical conditioning. In M. R. Jones (Ed.), Miami symposium on the prediction of behavior: Aversive stimulation (pp. 9-31). Miami: University of Miami Press.

Kimmel, H. D., LAChNit, H. (in press). The Rescorla-Wagner theory does not predict contextual control of phasic responding in transswitching. Biological Psychology.

MACKINTOSH, N. J. (1983). Conditioning and associative leaming. Oxford: Clarendon Press.

Pavlov, I. P. (1927). Conditioned reflexes. Oxford: Oxford University Press.

Rescorla, R. A., Wagner, A. R. (1972). A theory of Pavlovian conditioning: Variations in the effectiveness of reinforcement and nonreinforcement. In A. H. Black \& W. F. Prokasy (Eds.), Classical conditioning 2 (pp. 64-99). New York: Appleton-Century-Crofts.

(Manuscript received February 10, 1988;

revision accepted for publication April 22, 1988.) 